М. ПШЕЛЕНЩКИ

\title{
ИЗ СЕМАНТИКИ ЧАСТИЧНО ОПРЕДЕЛЕННЫХ ПОНЯТИЙ
}

\author{
(Р е 3 ю м е)
}

Предметом обсуждения являются в данной работе термины введенные в язык при помощи условных определений. В первой части работы выявлены различные типы высказываний, содержащих эти термины. Самый вазжный из них это класс „неопределенных” высказываний, т. е. таких высказываний, которые изменяют свое логическое значение в зависимости от такой или иной - согласной его определению - интерпретации термина определяемого условно. Автор указывает, что этот класс эквивалентен классу высказываний из которых этот условно опредляемый термин невозможно на основе такого определения элиминировать.

Во второй части работы рассматривается проблема логического значения „неопределенных” высказываний. Автор, пользуясь „релятивньп" понятием истинности в модели, формулирует известные из литературы попытки определить „абсолютное” понятие истинности применительно к языкам содержащим „неопределенные” высказывания а также рассматривает следствия отдельных решений. Анализируется также проблема предметного отношения терминов определяемых условно. Представлены главные типы определений понятий обозначения и называния в применении к терминами определяемым условно. 